\title{
CORRECTION
}

\section{Correction to: Characterization and analysis of specific energy consumption in the Brazilian agricultural sector}

\author{
T. Forster-Carneiro ${ }^{1} \cdot$ M. D. Berni ${ }^{2} \cdot$ D. Lachos-Perez ${ }^{1} \cdot$ J. Prado $^{3} \cdot$ I. L. Dorileo ${ }^{4} \cdot$ M. A. Rostagno ${ }^{5}$
}

Published online: 27 December 2017

(c) Islamic Azad University (IAU) 2017

\section{Correction to: \\ Int. J. Environ. Sci. Technol. (2017) 14:2077-2092 \\ https://doi.org/10.1007/s13762-017-1311-5}

The original version of this article unfortunately contained a mistake: Juliane Prado was not listed among the authors. The complete authors are given above.

The original article can be found online at https://doi.org/10.1007/ s13762-017-1311-5.

T. Forster-Carneiro

taniafc@unicamp.br

1 Department of Food Engineering, University of Campinas UNICAMP, Campinas, Brazil

2 Interdisciplinary Centre of Energy Planning, University of Campinas - UNICAMP, Campinas, Brasil

3 Centro de Ciências da Natureza (CCN), Federal University of São Carlos (UFSCar), Campus Lagoa do Sino, Buri, São Paulo, Brazil

4 Interdisciplinary Centre of Studies for Energy Planning, Federal Universityof Mato Grosso - UFMT, Cuiaba, Brazil

5 School of Applied Sciences, University of Campinas FCA/UNICAMP, Limeira, Brazil 